\title{
Papers
}

\section{Serum and tissue measurements of CA72-4 in patients with endometrial carcinoma}

\author{
H Hareyama, N Sakuragi, S Makinoda, S Fujimoto
}

\begin{abstract}
Aims-To evaluate the clinical usefulness of CA72-4 as a serum tumour marker for endometrial carcinoma and to investigate its immunohistochemical localisation in endometrial carcinoma cells.
\end{abstract}

Methods-Serum concentrations of CA72-4 were determined in 72 patients with endometrial carcinoma. Immunohistochemical localisation of CA72-4 was investigated using the streptavidin-biotin method, using monoclonal antibodies B72.3 and CC49.

Results-Serum CA72-4 was increased above the cut off value in $31.9 \%$ of the patients with endometrial carcinoma. Serum CA72-4 positivity was correlated with depth of myometrial invasion, adnexal metastasis, lymphovascular space involvement, and pelvic and para-aortic lymph node metastasis. Multivariate analysis showed a significant correlation between serum CA72-4 positivity and adnexal metastasis. The serum concentrations of CA125 and CA19-9, which could be tumour markers for endometrial carcinoma, were measured at the same time. In seven of 72 patients increased concentrations of serum CA72-4 were found while those for CA125 and CA19-9 were within the normal ranges; in four of the seven patients the disease had spread beyond the uterus. Immunohistochemical positivity for CA72-4 antigen was $\mathbf{7 6 . 9 \%}$ and occurred in the tumour cell membrane and cytoplasm. There was no significant difference in immunohistochemical positivity between patients with increased CA72-4 and those with normal CA72-4 values.

Conclusions-The measurement of serum concentrations of $\mathrm{CA}$ 72-4 could be useful for predicting and monitoring the progress of disease-for example, extracorporeal spread.

(F Clin Pathol 1996;49:967-970)

Correspondence to:

Dr S Fujimoto.

Accepted for publication 11 September 1996
Keywords: endometrial carcinoma, CA72-4, tumour marker.
The squamous cell carcinoma (SCC) antigen for cervical squamous cell carcinoma and the $i$ CA125 antigen for primary common epithelial ovarian carcinoma, especially serous cystad- ? enocarcinoma, have been reported to be useful o gynaecological serum tumour markers. How- 0 ever, clinically useful markers for endometrial carcinoma are not so well established. ${ }^{12}$

CA72-4 is defined by its reactivity with two monoclonal antibodies B72.3 and CC49. ${ }^{34}$ We evaluated the clinical usefulness of CA72-4 as a serum tumour marker for endometrial carcinoma and examined the association between serum CA72-4 positivity and various clinicopathological findings. We also investigated the immunohistochemical localisation of CA72-4 in endometrial carcinoma tumour cells.

\section{Methods}

Seventy two patients with endometrial carcinoma, with a mean (SD) age of 56.5 (7.9) years (range 35-72 years), were treated in our department from February 1987 to October 1993. Serum samples were obtained before surgery. Histological types were: adenocarci- 3 noma of endometrioid type (59 patients); $\delta$ adenoacanthoma $(n=5)$; adenosquamous cell carcinoma $(n=4)$; clear cell carcinoma $(n=3)$; 옥 and serous papillary carcinoma $(n=1)$. Tu- $D$ mours were staged as follows: stage IA $(n=7)$, 글 IB $(n=24)$, IC $(n=7)$, IIA $(n=1)$, IIB $(n=4)$, N IIIA $(n=17)$, IIIC $(n=7)$, and IVB $(n=5)$, all according to FIGO (1988) criteria. Twenty nine patients were judged to have grade $1 \omega$ tumours, 31 grade 2 , and 12 grade 3 . When the tumour was confined to the uterine corpus, a $\stackrel{0}{\frac{0}{\Phi}}$ modified radical hysterectomy, bilateral $\stackrel{\oplus}{\oplus}$ salpingo-oophorectomy, and pelvic and paraaortic lymphadenectomy were performed. The $\vec{O}$ same procedures were used for those with $\triangle$ spread into the cervix. If the tumour had $\mathbb{D}$ extended beyond the uterus a hysterectomy, bilateral salpingo-oophorectomy, resection of $\delta$ the metastatic tumour as extensively as possible, and lymph node sampling were carried out.

Serum concentrations of CA72-4 were determined using a two site radioimmunometric assay kit, using the two monoclonal antibodies B72.3 and CC49 (CA72-4 kit Centcor Co, Ltd, USA). The serum concentrations of CA125 and 
Table 1 Incidence of increased serum concentrations of CA72-4, CA125, and CA19-9 in patients with endometrial carcinoma

\begin{tabular}{llll}
\hline \multicolumn{2}{l}{ Tumour markers } & & \\
\cline { 1 - 2 } CA72-4 & CA125 & CA19-9 & No of patients (\%) \\
\hline+ & + & + & $8(11.1)$ \\
+ & + & - & $6(8.3)$ \\
+ & - & + & $2(2.8)$ \\
- & + & + & $5(6.9)$ \\
+ & - & - & $7(9.7)$ \\
- & + & - & $3(4.2)$ \\
- & - & + & $4(5.6)$ \\
- & - & - & $37(51.4)$ \\
Total & & & $72(100)$
\end{tabular}

$+=$ more than or equal to cut off for each tumour marker (CA72-4 < $4 \mathrm{U} / \mathrm{ml}$, CA125 < $35 \mathrm{U} / \mathrm{ml}$, CA19-9 < $37 \mathrm{U} / \mathrm{ml}$ ); $=$ less than cut off.

CA19-9 were simultaneously measured using CA125 and CA19-9 radiometric assay kits (Centcor Co., Ltd, USA), respectively. In this study a serum concentration for CA72-4 above 4 $\mathrm{U} / \mathrm{ml}$ was defined as being abnormally high. ${ }^{5} \mathrm{Cut}$ off values of $35 \mathrm{U} / \mathrm{ml}$ and $37 \mathrm{U} / \mathrm{ml}$ were used for CA125 and CA19-9, respectively.

Immunohistochemical localisation of CA72-4 in endometrial carcinoma was investigated using B72.3 and CC49 (Toray-Fuji Bionics Inc., Tokyo, Japan). Immunohistochemical staining was performed using the streptavidin-biotin technique. Paraffin wax embedded sections were dewaxed in xylene and dehydrated in serially diluted alcohol. Endogenous peroxidase activity was blocked by $0.6 \%$ hydrogen peroxide in methanol. Sections were washed in phosphate buffered saline (PBS) for five minutes. The incubation time was set at 20 minutes with B72.3 and CC49. After rinsing in PBS the sections were incubated sequentially with biotinylated horse anti-mouse IgG, followed by incubation with streptavidin-peroxidase complexes. After each incubation step the sections were rinsed for five minutes with three changes of PBS. The staining was developed for five minutes in a freshly prepared solution of 3-amino-9-ethyl-carbazol and counterstained with haematoxylin.

The Wilcoxon test, $\chi^{2}$ test, and multiple logistic regression analysis were used for statistical analysis.

\section{Results}

Among 72 patients with endometrial carcinoma, serum positivity for CA72-4 was noted in $31.9 \%(23 / 72)$. Among patients with benign

Table 2 Endometrial carcinoma with raised serum CA72-4 and normal concentrations of CA125 and CA19-9

\begin{tabular}{|c|c|c|c|c|c|c|c|c|}
\hline \multirow[b]{2}{*}{$\begin{array}{l}\text { Case } \\
\text { No }\end{array}$} & \multirow[b]{2}{*}{ Histology } & \multirow[b]{2}{*}{$\begin{array}{l}\text { Surgical } \\
\text { stage }\end{array}$} & \multirow[b]{2}{*}{$\begin{array}{l}\text { Adnexal } \\
\text { metastasis }\end{array}$} & \multicolumn{2}{|c|}{ Lymph node metastasis } & \multicolumn{3}{|c|}{$\begin{array}{l}\text { Serum concentrations * } \\
(U / m l)\end{array}$} \\
\hline & & & & $\begin{array}{l}\text { Pelvic } \\
\text { lymph node }\end{array}$ & $\begin{array}{l}\text { Para-aortic } \\
\text { lymph node }\end{array}$ & $C A 72-4$ & $C A 125$ & CA19-9 \\
\hline 1 & $\mathrm{ADC}$ & IVB & - & + & + & 163.0 & 30.9 & 23.9 \\
\hline 2 & $\mathrm{ADC}$ & IB & - & - & - & 12.0 & 22.4 & 11.8 \\
\hline 3 & $\mathrm{CC}$ & IIIC & - & + & + & 9.5 & 20.7 & 8.0 \\
\hline 4 & ADC & IC & - & - & - & 7.8 & 22.9 & 17.8 \\
\hline 5 & ADA & IIIA & + & - & - & 7.1 & 23.5 & 21.0 \\
\hline 6 & $\mathrm{ADC}$ & IB & - & - & - & 7.0 & 15.7 & 6.4 \\
\hline 7 & ADC & IIIA & - & - & - & 4.1 & 6.3 & 7.0 \\
\hline
\end{tabular}

* The cut off values for CA72-4, CA125, and CA19-9 were 4, 35, and $37 \mathrm{U} / \mathrm{ml}$, respectively. $\mathrm{ADC}=$ endometrioid type adenocarcinoma; $\mathrm{CC}=$ clear cell carinoma; $\mathrm{ADA}=$ adenoacanthoma
Table 3 Serum concentrations of CA72-4 in relation to surgical stage in patients with endometrial carcinoma

\begin{tabular}{llll}
\hline Surgical stage & $n$ & $\begin{array}{l}\text { Mean }(S E) \\
C A 72-4(U / m l)\end{array}$ & Positivity (\%) \\
\hline I & 38 & $3.9(0.5)$ & 18.4 \\
II & 5 & $4.5(2.4)$ & 20.0 \\
III & 24 & $12.1(4.8)$ & 41.7 \\
IV & 5 & $347.9(281.7)$ & 100.0
\end{tabular}

Table 4 Relation between raised serum concentrations of CA72-4 and histological variable

\begin{tabular}{lllll}
\hline & \multicolumn{2}{c}{ Univariate } & & \multicolumn{2}{c}{ Multivariate* } \\
\cline { 2 - 2 } \cline { 5 - 5 } \cline { 5 - 5 } Variable & $p$ value & & $p$ value & Odds ratio \\
\hline Grade & 0.5565 & & & \\
Myometrial invasion & 0.0040 & & 0.3583 & 0.494 \\
LVSI & 0.0041 & & 0.1826 & 0.356 \\
PLN & 0.0291 & & 0.9481 & 0.913 \\
PAN & 0.0142 & & 0.5086 & 0.376 \\
Cervical invasion & 0.1634 & & & \\
Adnexal metastasis & 0.0051 & & 0.0437 & 0.160 \\
Peritoneal cytology & 0.0625 & & & \\
\hline
\end{tabular}

NS $=$ not significant $;$ LVSI $=$ lymphovascular space involvement; PLN = pelvic lymph node metastasis; $\mathrm{PAN}=$ para-aortic lymph node metastasis.

${ }^{\star}$ Histological variables that did not reach significance by univariate analysis were excluded from multivariate analysis.

disease, on the other hand, an increased serum CA72-4 concentration was observed in only $5.6 \%$ (4/72). Abnormally high serum CA72-4 concentrations were noted in $20(31.3 \%)$ cases among 59 patients with adenocarcinoma and five with adenoacanthoma, one of four with adenosquamous carcinoma, one of three with clear cell carcinoma, and one with serous papillary carcinoma. For the 72 patients with endometrial carcinoma, we measured the serum CA125 and CA19-9 concentrations simultaneously. The concentrations of all three serum markers, CA72-4, CA125, and CA19-9, were increased in eight patients $(11.1 \%)$, and $13(18 \%)$ had increased concentrations of two markers. Only one of these tumour marker concentrations was increased in 14 patients (19.5\%) (table 1). In seven CA125 and CA19-9 were normal but serum CA72-4 was increased; and in four of these seven patients the disease had progressed beyond the uterus (tables 1 and 2).

Average serum concentrations of CA72-4 were $3.9 \mathrm{U} / \mathrm{ml}$ in surgical stage $\mathrm{I}, 4.5 \mathrm{U} / \mathrm{ml}$ in stage II, $12.1 \mathrm{U} / \mathrm{ml}$ in stage III, and $347.9 \mathrm{U} / \mathrm{ml}$ in stage IV. The values tended to be higher the more advanced the stage of disease (table 3 ). There was a significant correlation between CA72-4 positivity and surgical stage of the disease $(\mathrm{p}<0.05)$ (table 3$)$.

Increased concentrations of serum CA72-4 were found in only seven of 38 patients $(18.4 \%)$ in whom the disease was confined to the uterus (the uterine corpus alone or the uterine corpus and the cervix). The serum CA72-4 value was within the normal range in all seven patients whose disease was limited to the endometrium. On the other hand, 16 of 34 $(47.1 \%)$ patients with histologically or cytologically confirmed spread of the disease beyond the uterus had raised serum CA72-4 concentrations. The positivity for the group in whom the disease had progressed outside the uterus was significantly higher than for those 
Table 5 Relation between serum CA72-4 and immunohistochemical positivity of CA72-4 by monoclonal antibodies B72.3 and CC49 in endometrial carcinoma

\begin{tabular}{lll}
\hline $\begin{array}{l}\text { Serum } C A 72-4 \\
(U / m l)\end{array}$ & $\begin{array}{l}\text { No of } \\
\text { patients }\end{array}$ & $\begin{array}{l}\text { Immunohistochemical staining } \\
(\text { positive }(\%))\end{array}$ \\
\hline$>4$ & 10 & $10(100.0)$ \\
$\leq 4$ & 16 & $10(62.5)$ \\
Total & 26 & $20(76.9)$
\end{tabular}

whose lesions were confined to the endometrium $(\mathrm{p}<0.05)$ or the myometrium $(\mathrm{p}<0.05)$. An increased serum CA72-4 concentration was seen in eight of $44(18.2 \%)$ patients who had myometrial spread of less than $50 \%$, and in 15 of 28 patients $(53.6 \%)$ who had myometrial spread involving more than $50 \%$ of the uterus. The reactivity for the group with myometrial infiltration exceeding $50 \%$ was significantly higher than in those with myometrial infiltration of less than $50 \%$ $(p<0.005)$. Thirty seven of 72 patients $(51.4 \%)$ had lymphovascular space involvement. An increased serum CA72-4 concentration was observed in 18 of 37 patients $(48.7 \%)$ with lymphovascular space involvement and in five of 35 patients $(14.3 \%)$ without. The reactivity

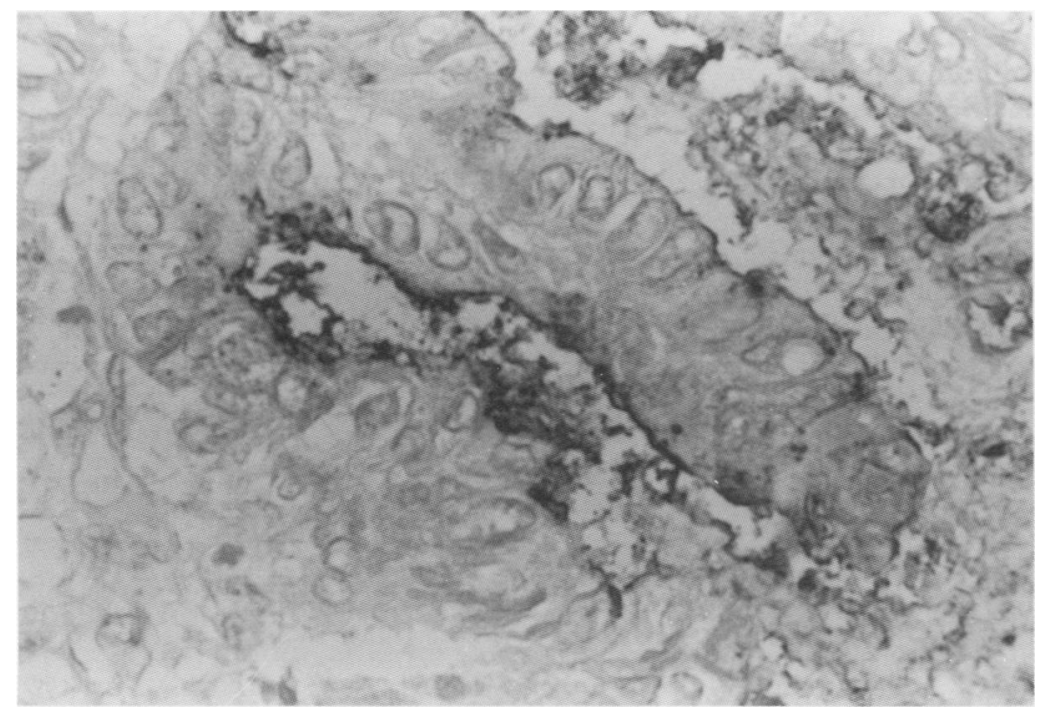

Figure 1 Endometrial carcinoma stained for B72.3. Glandular epithelium surface shows strong staining.

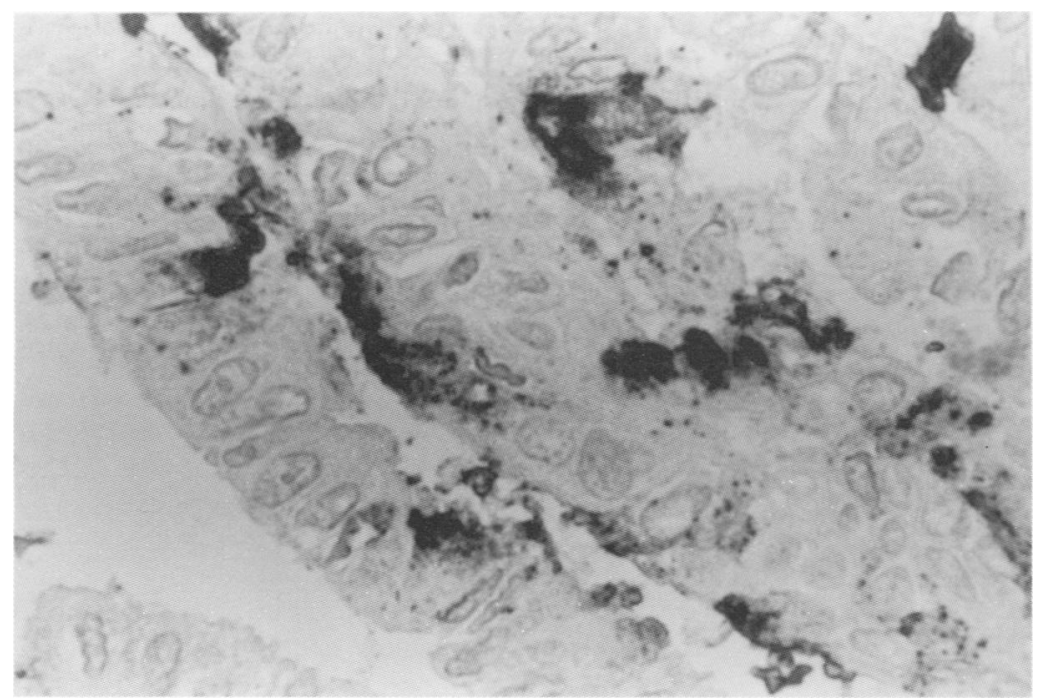

Figure 2 Endometrial carcinoma stained for B72.3. Cytoplasm of glandular epithelium is strongly stained. for the group with lymphovascular space involvement was significantly greater than that for the group without $(\mathrm{p}<0.005)$. Adnexal metastasis was observed in 11 cases $(15.3 \%)$. Increased serum CA72-4 was seen in 15 of 61 patients $(24.6 \%)$ who had no adnexal metastasis and in eight of the 11 patients $(72.7 \%)$ who had adnexal metastasis. The reactivity of the group with adnexal metastasis was significantly higher than that for the group with no adnexal metastasis $(p<0.01)$. Of 70 patients, there were nine $(12.9 \%)$ with pelvic lymph node metastasis. A rise in serum CA72-4 value was observed in 15 of 61 patients $(24.6 \%)$ who had no pelvic lymph node metastasis and in six of nine patients $(66.7 \%)$ with pelvic lymph node disease. Among 71 patients, eight $(11.3 \%)$ had para-aortic lymph node metastasis. An increased serum CA72-4 concentration was observed in six of eight patients $(75.0 \%)$ with para-aortic lymph node metastasis and in 16 of the 63 patients $(25.4 \%)$ without. CA72-4 reactivity for both pelvic and para-aortic lymph node metastasis groups was significantly higher than that for the groups without $(p<0.05$ for each). However, no significant correlation could be demonstrated between an increase in CA72-4 and the peritoneal cytology, histological grading, and cervical invasion (table 4). Multiple logistic regression analysis showed that there was a significant correlation between an increase in serum CA72-4 and adnexal metastasis (table 4).

The staining of monoclonal antibodies B72.3 and CC49 was examined in primary tissue samples from 26 patients with endometrial carcinoma. Staining with B72.3 was generally equal to that of CC49. In 20 of 26 cases (76.9\%) with endometrial carcinoma, CA72-4 reactivity was observed immunohistochemically in the tumour cell membrane and cytoplasm (figs 1 and 2). Immunohistochemical staining was $100 \%$ for the group with increased serum CA72-4 concentration, while it was $62.5 \%$ for the group with normal values (table 5).

\section{Discussion}

Until now, the histological type and grade, myometrial invasion, lymphovascular space $N$ involvement, and retroperitoneal lymph node metastasis have been regarded as the major factors influencing the prognosis of endometrial carcinoma. ${ }^{6-11}$ Strategies for treatment would be much more effective if the extent of the disease could be predicted preoperatively by measuring serum tumour markers.

Bast et al showed an $80 \%$ positivity for ovarian carcinoma by measuring the serum CA 125 value. $^{2}$ This marker is especially useful for serous cystadenocarcinoma and is now being used clinically as the main tumour marker. However, there is no comparable tumour marker for endometrial carcinoma. There have been several previous reports on the positivity for various tumour markers in endometrial carcinoma, but these have been on investigations of CA125 and CA19-9, both of which had a low positivity of $25 \% .{ }^{12}{ }^{13}$ Niloff et al reported that an increase in serum CA125 
confirms progress or a recurrence in endometrial carcinoma. ${ }^{14}$ Patsner et al reported that serum CA125 positivity was confirmed in $93.3 \%$ (28 of 31) of patients in surgical stages III and IV of endometrial carcinoma and in $98 \%$ ( 57 of 58) of patients in stages I and II but with normal serum CA125 concentrations. ${ }^{15}$ However, careful judgment is required because high CA125 concentrations are often observed in endometriosis, peritonitis, and during menstruation. ${ }^{16}{ }^{17}$

CA72-4 is an antigenic tumour associated glycoprotein (TAG-72) which reacts with mouse monoclonal antibody B72.3, directed against the membrane component fraction of mammary carcinoma metastasising the liver, and mouse monoclonal antibody CC49 which is extracted and refined from cultured colon cancer cells LS-174T3. Serum CA72-4 is associated with a low false positivity in ovarian cancer and has been shown to be a useful marker that compensates for its false positive rate in mucinous cystadenocarcinoma. ${ }^{18} \mathrm{Pr}$ eoperative serum concentrations of CA72-4, which tend to be higher with increased dissemination of gastric cancer cells, may be a more reliable tumour marker than carcinoembryonic antigen (CEA). ${ }^{19}$ However, there have been few studies on serum CA72-4 in relation to endometrial carcinoma. Soper et al have shown a $23.9 \%$ positivity for CA72-4 in endometrial carcinoma and reported that a group with the lesion limited to the uterus showed a $4 \%$ positive rate; those with metastasis had $30 \%$ positivity. ${ }^{20}$

In this study we measured the preoperative concentration of serum CA72-4 in 72 patients with endometrial carcinoma and found a positivity of $31.9 \%$. CA72-4 immunohistochemical positivity was $76.9 \%$ and localised in the tumour cell membrane and cytoplasm. Notably, immunohistochemical localisation was found in all the patients whose serum CA72-4 value was increased. Both the actual value and the positivity of serum CA72-4 increased as the disease progressed. Although it is generally difficult to evaluate the correlation between a tumour marker and various histopathological findings, the results of this study indicate that the prevalence of increased CA72-4 concentrations was significantly higher when there was deep myometrial invasion, adnexal metastasis, lymphovascular space involvement, and pelvic and para-aortic lymph node metastasis. However, no significant difference was observed between increased serum CA72-4 and histological grade, cervical invasion, or peritoneal cytology. Multivariate analysis showed a probable correlation between a preoperative in- crease in serum CA72-4 concentration and a higher risk of adnexal metastasis. Seven patients in this study also had a high CA72-4 value while CA125 and CA19-9 concentrations were normal, and in four of these seven patients extracorporeal spread of the disease was confirmed surgically. This suggests that measuring the serum CA72-4 concentration may be useful for preoperative prediction of the progress of the disease outside the uterus, as well as for effective treatment and monitoring of the clinical course of the disease.

1 Kato $\mathrm{H}$, Torigoe T. Radioimmunoassay for tumour antigen of human cervical squamous cell carcinoma. Cancer 1977;40:1621-8.

2 Bast RC, Feeney M, Lazaras H, Nadler LM , Colvin RB, Knapp RC. Reactivity of a monoclonal antibody with human ovarian carcinoma. 7 Clin Invest 1981;68:1331-7.

3 Colcher D, Hand P H, Nuti M, Schlom J. A spectrum of monoclonal antibodies reactive with human mammary monoclonal antibodies reactive with human mamm.

4 Paterson A, Schlom J, Sears HF, Bennett J, Colcher D Radioimmunoassay for the detection of a human tumor associated glycoprotein (TAG-72) using monoclonal antibody B72.3. Int $\mathcal{F}$ Cancer 1986;37:659-66.

5 Shitara M, Yoshioka H, Sakurabashi I, Kawai T. Fundamental studies and the reference values of cancer associated antigen TAG-72 (CA72-4). Rinsho Byori 1988;36:117781 .

6 Lotocki RJ, Coprland LJ, Depetrillo AD, Muirhead W. Stage I endometrial adenocarcinoma treatment results in 835 patients. Am f Obstet Gynecol 1983;146:141-5.

7 Aalders J, Abeler V, Kolstad PL, Onstrud M. Postoperative external irradiation and prognostic parameters in stage endometrial carcinoma. Obstet Gynecol 1980;56:419-27.

8 Chen SS, Lee L. Retroperitoneal lymph node metastasis in stage I carcinoma of the endometrium - Correlation with risk factors. Gynecol Oncol 1983;16:319-25.

9 Piver MS, Yazigi R, Blumenson L, Tsukada Y. A prospective trial comparing hysterectomy, hysterectomy plus vaginal radium, and uterine radium plus hysterectomy in stage I radium, and uterine radium plus hysterectomy in sta

10 Christopherson WM, Connelly PJ, Alberhansky RC. Carcinoma of the endometrium. Cancer 1983;51:1705-9.

11 Hanson M B, Nagel JRV, Powell DE, Donaldson ES, Gallion $\mathrm{H}$, Mehige $\mathrm{M}$, et al. The prognostic significance of lympho-vascular space invasion in stage I endometrial cancer. Cancer 1985;55:1753-7.

12 Duk JM, Aalders JG, Feuren GJ, de Bruijin HWA. A useful marker in endometrial carcinoma. Am $\mathcal{f}$ Obstet Gynecol 1986;155:1057-8.

13 Takeshima N, Shimizu Y, Umezawa S, Hirai Y, Chen JT, Fujimoto I, et al. Combined assay of serum levels of CA125 and CA19-9 in endometrial carcinoma. Gynecol Oncol 1993;48:148-54.

14 Niloff JM, Klug TL, Scaetzl E, Zurawski VR, Knapp RC, Bast RC. Elevation of serum CA125 in carcinomas of the fallopian tube, endometrium and endocervix. Am $\mathcal{F}$ Obstet Gynecol 1984;148: 1057-8.

15 Patsner BP, Mann WJ, Cohen H, Loesch M. Predictive value of preoperative serum CA125 levels in clinically localized and advanced endometrial carcinoma. $A m \mathcal{f}$ Obstet Gynecol 1988;158:399-402.

16 Pittaway DE, Fayez JA. Serum antigen levels increase during menses. Am f Obstet Gynecol 1987;156:75-6.

17 Pittaway DE, Fayez JA. The use of CA125 in the diagnosis and management of endometriosis. Fertil Steril 1986;46: 790-5.

18 Negishi Y, Iwabuchi $H$, Sakunaga $H$, Sakamoto $M$, Okabe $\mathrm{K}$, Sato $\mathrm{H}$, et al. Serum and tissue measurements of CA72-4 in ovarian cancer patients. Gynecol Oncol 1993;48. 148-54.

19 Hamazoe R, Maeta M, Matsui T, Shibata S, Shiota S, Kaibara N. CA72-4 compared with carcinoembryonic antigen as a tumor marker for gastric cancer. Eur $\mathcal{F}$ Cancer 1992;28: as a tum.

20 Soper JT, Berchuck A, Olt GJ, Soisson AP, Claeke-Pearson DL, Bast RC. Preoperative evaluation of serum CA125, TAG72 and CA15-3 in patients with endometrial carcinoma. Am f Obstet Gynecol 1990;163:1204-9. 